\title{
Physical Activity Behavior from a Transdisciplinary Biopsychosocial Perspective: a Scoping Review
}

\author{
Jannika M. John ${ }^{1,2^{*}} \mathbb{D}$, Vanessa Haug ${ }^{1}$ and Ansgar Thiel ${ }^{1,2}$
}

\begin{abstract}
Background: Physical activity behavior is a complex and multidimensional phenomenon. For its analysis, transdisciplinary biopsychosocial approaches yield great potential. In health research, the biopsychosocial model has experienced a renaissance. Researchers have tried to grasp the complex interplay of biological, psychological, and social factors. With this scoping review, we aimed to examine how the 'biopsychosocial' has been conceptualized in scientific work related to physical activity behavior.

Methods: The scoping review was informed by the PRISMA guidelines for scoping reviews (PRISMA-ScR). A systematic literature search was conducted in Web of Science, SportDiscus, PsycArticles, Psyclnfo, and PubMed. Only articles published in peer-reviewed journals that contained all three components of a biopsychosocial approach (e.g., bio/physio/genetic, psycho/mental, and socio/cultural/environmental) were included. We only included articles in our narrative synthesis that integrated physical activity behavior into a biopsychosocial model, or investigated or described physical activity behavior on the basis of such a model.

Results: Thirteen studies met the inclusion criteria; eight articles pursued a biopsychosocial approach in the tradition of Engel, five employed a socio-ecological approach. The models in the analyzed articles referred to either correlates of physical activity behavior, or the influence of physical activity on health or aging. Only a minority of the articles, however, referred to interactions between biological, psychological, and social factors.

Conclusions: The included articles were quite heterogeneous in their approach to physical activity from a biopsychosocial perspective. The included articles illustrate that the adoption of a biopsychosocial perspective may assist to capture and understand the complex phenomenon of physical activity behavior and might inform future transdisciplinary physical activity research.
\end{abstract}

Keywords: Biopsychosocial, Physical activity, Socio-ecological, Framework, Approach, Scoping review

\footnotetext{
* Correspondence: jannika.john@uni-tuebingen.de

${ }^{1}$ Institute of Sports Science, Eberhard Karls University Tübingen,

Wilhelmstraße 124, 72074 Tübingen, Germany

${ }^{2}$ Interfaculty Research Institute for Sport and Physical Activity, Eberhard Karls

University Tübingen, Tübingen, Germany
}

\section{Springer Open}

(c) The Author(s). 2020 Open Access This article is licensed under a Creative Commons Attribution 4.0 International License, which permits use, sharing, adaptation, distribution and reproduction in any medium or format, as long as you give appropriate credit to the original author(s) and the source, provide a link to the Creative Commons licence, and indicate if changes were made. The images or other third party material in this article are included in the article's Creative Commons licence, unless indicated otherwise in a credit line to the material. If material is not included in the article's Creative Commons licence and your intended use is not permitted by statutory regulation or exceeds the permitted use, you will need to obtain permission directly from the copyright holder. To view a copy of this licence, visit http://creativecommons.org/licenses/by/4.0/. 


\section{Key Points}

- The complex and dynamic nature of physical activity behavior requires a transdisciplinary perspective integrating the interplay of biological, psychological, and social factors.

- Existing literature does not give clear answers on how biological, psychological, and social factors are interwoven with regard to the uptake, maintenance, and effectiveness of physical activity behavior.

- The present scoping review not only shows the potential of looking at physical activity behavior from a biopsychosocial perspective but also highlights the need for further empirical and conceptual research in this area.

\section{Introduction}

There is a broad agreement among researchers that physical activity (PA) is a multidimensional and complex phenomenon. Its analysis therefore requires complex, biopsychosocial approaches [1] that can enable a "better understanding of those characteristics of individuals that are important in terms of the uptake, acceptance and maintenance of physical activity" [2]. Biopsychosocial analyses in the context of health and illness were particularly influential in the 1970s and 1980s. In the following decades, health research more and more shifted to mono-disciplinary studies. However, in recent years, the biopsychosocial model has experienced a veritable renaissance in the field of health and illness research [3]. This development could be the result of a demand, spread globally by the WHO, that health should be analyzed from a holistic perspective [4]. Hence, many studies on health and illness have tried to grasp the interplay of biological, psychological, and social factors [5].

In research on PA behavior, multidisciplinary perspectives are almost "state of the art." However, this does not necessarily mean that the studies are based on a holistic perspective. In order to examine whether the "biopsychosocial" has also become a standard in PA research, we are therefore particularly interested in the question, to which extent research in the area of PA claims to follow a biopsychosocial paradigm. Hence, the present scoping review aims to answer the question, which theoretical and conceptual frameworks exist for the analysis of PA behavior from a biopsychosocial perspective.

\section{Biopsychosocial Models of Health and Illness}

In general, the biopsychosocial is understood as a holistic perspective on a variety of phenomena [6]. Due to the complexity of most phenomena, the single components are therefore not considered as isolated entities, but their dimensional interactions characterize the phenomenon under question. In the context of health and illness, most definitions of the "biopsychosocial" refer to Engel's biopsychosocial model for the explanation of health and illness [7].

This holistic biopsychosocial perspective emerged as a response to the recurring criticism of the dualistic view on body and mind and reductionism [6]. In the biopsychosocial model of health and illness, the single components at the individual system level (i.e., biological, psychological, and social) are not considered independently of each other, but the main focus is on their interactions [8]. It is precisely these interactions that stand in contrast to a purely biomedical approach where disturbances or functional constraints would only be considered at the respective system level without paying attention to the levels above or below. In contrast, health and illness in the biopsychosocial disease model are always dependent on the functionality of all individual levels and the handling of disturbances at each level. The strength of such an approach is that health and illness are not conceptualized as fixed phenomena, but as dynamic events based on the interactions between the different system levels.

\section{Physical Activity From a Biopsychosocial Perspective}

Such a systemic and dynamic perspective also holds potential for conceptualizing PA, which is also a highly complex, dynamic, and multidimensional behavioral phenomenon $[9,10]$. In recent years, the number of multidisciplinary perspectives on PA has continually increased. Today, there is a broad consensus that PA has a high potential for promoting public health due to its various positive biopsychosocial effects. From a biological perspective, many positive effects of PA, such as the prevention of diseases of the musculoskeletal system [11] and the cardiovascular system [12], are considered evidence-based. It is also widely accepted that PA has psychological effects, such as the reduction of symptoms of depression or increasing self-esteem in children and adults [12]. Social benefits of PA, such as the integration of people with a migration background, the ability to work in a team, or social interaction with others [13], are also often described, although the degree of evidence is rather low compared to the other dimensions. Taken together, the effects of PA can be described from a biopsychosocial perspective. This also applies to the correlates of PA behavior. In this regard, PA behavior is influenced by biological factors, such as genetics [2, 14], the individual state of health, psychological aspects such as motivation or affect, or social factors such as social support from significant others $[12,15]$.

However, existing literature does not give clear answers on how the biological, psychological, and social 
factors are interwoven with regard to the uptake, maintenance, and effectiveness of PA behavior. In order to get a clearer picture of what we know and do not know about the biopsychosocial analysis of PA behavior, we aim to review theoretical approaches that try to explain the correlates and effects of PA behavior from a transdisciplinary biopsychosocial perspective and integrate the interactions between the different components in their models $[16,17]$.

On this basis, this scoping review attempts to (a) provide an overview of theoretical and conceptual biopsychosocial frameworks related to PA behavior, (b) critically discuss how the biopsychosocial perspective is applied to research in the field of PA behavior, (c) identify key characteristics of research conducted from a biopsychosocial perspective, and (d) provide implications for future transdisciplinary PA research in the context of health promotion, disease prevention, and rehabilitation and treatment.

\section{Methods}

The method for this scoping review was informed by the preferred reporting items for systematic reviews and meta-analyses extension for scoping reviews (PRISMAScR) guidelines [18]. We chose a scoping review approach because it is particularly suitable for determining the scope of a body of literature on a rather broad topic [19]. With regard to our research question, a scoping review approach allows us to investigate how the "biopsychosocial" has been conceptualized in the existing literature on PA behavior, to assess which biological, psychological, and social factors have been considered in research conducted from a biopsychosocial perspective, and to identify knowledge gaps in an attempt to provide implications for future transdisciplinary work in the field of PA research.

\section{Literature Search}

We used the databases Web of Science, SportDiscus, PsycArticles, PsycInfo, and PubMed for the search. Additional references were identified through screening of reference sections of eligible studies. No publication date limitation was set. The search was deliberately not limited to a publication period or the type of publication in order to generate a complete overview of the available literature.

The last search was carried out on 24 June 2020, using the following search strategy with English and German search terms for all databases: (biopsychosocial OR "biopsycho-social" OR transdisciplinary OR biopsychosozial OR transdisziplinär) AND ("physical activity" OR "körperliche Aktivität") AND (model OR framework OR approach OR perspective OR Modell OR Ansatz OR Perspektive). For the databases Web of Science and
PubMed the search setting "All Fields" was used, for the other databases the default settings were used.

Before selecting the search strategy described above, some search strategy revisions were made as part of the research process, staying true to the scoping approach of the present review [20]. In our initial search, we only searched for the term "biopsychosocial" and not for the term "transdisciplinary." However, this resulted in a rather low number of hits. Furthermore, when screening the respective texts, we noticed that the term "transdisciplinary" was often used interchangeably with the term "biopsychosocial." Hence, we adapted our search strategy accordingly and included "transdisciplinary" in our search strategy. We also attempted to add the search term "interdisciplinary." However, this generated too many hits, which is why we decided to abstain from including this term in our search strategy.

In this review, we aimed to focus on biopsychosocial approaches to PA behavior in daily life. Our analysis concentrates on PA as a generic form of bodily movement integrated into one's normal daily routine [21]. We have explicitly chosen to exclude sport and exercise from our search and analysis since both denote activities that take place in specifically structured settings with different aims. Sport as a distinct form of PA is characterized by an explicit focus on competition and performance. Exercise is practice with the aim of improving a specific ability or skill [22]. Hence, sport and exercise participation may also be influenced by different biological, psychological, social, and environmental factors and likely lead to different effects on the biological, psychological, and social level, which, as a consequence, would impede a synthesis of biopsychosocial approaches in the context of PA behavior from a more universal perspective. Additionally, the sole focus on lifestyle PA reflects the recent paradigm shift in the health literature from exercise promotion to a combination of PA promotion and reduction of sedentary time [23].

\section{Screening Process and Inclusion and Exclusion Criteria} Inclusion and exclusion criteria for each stage of the screening process (i.e., title, abstract, and full-text screening) were not predetermined but developed iteratively. Criteria were further refined and adapted as knowledge grew, which is in line with the notion of a scoping review [20].

Papers were included if they (i) focused on biological, psychological, and social factors influencing engagement in PA; (ii) examined biological, psychological, and social effects of PA behavior; (iii) were published in peerreviewed journals; (iv) were published in English or German; and (v) were available as full-texts.

Papers were excluded if (i) they did not contain all three components of a biopsychosocial approach (e.g., 


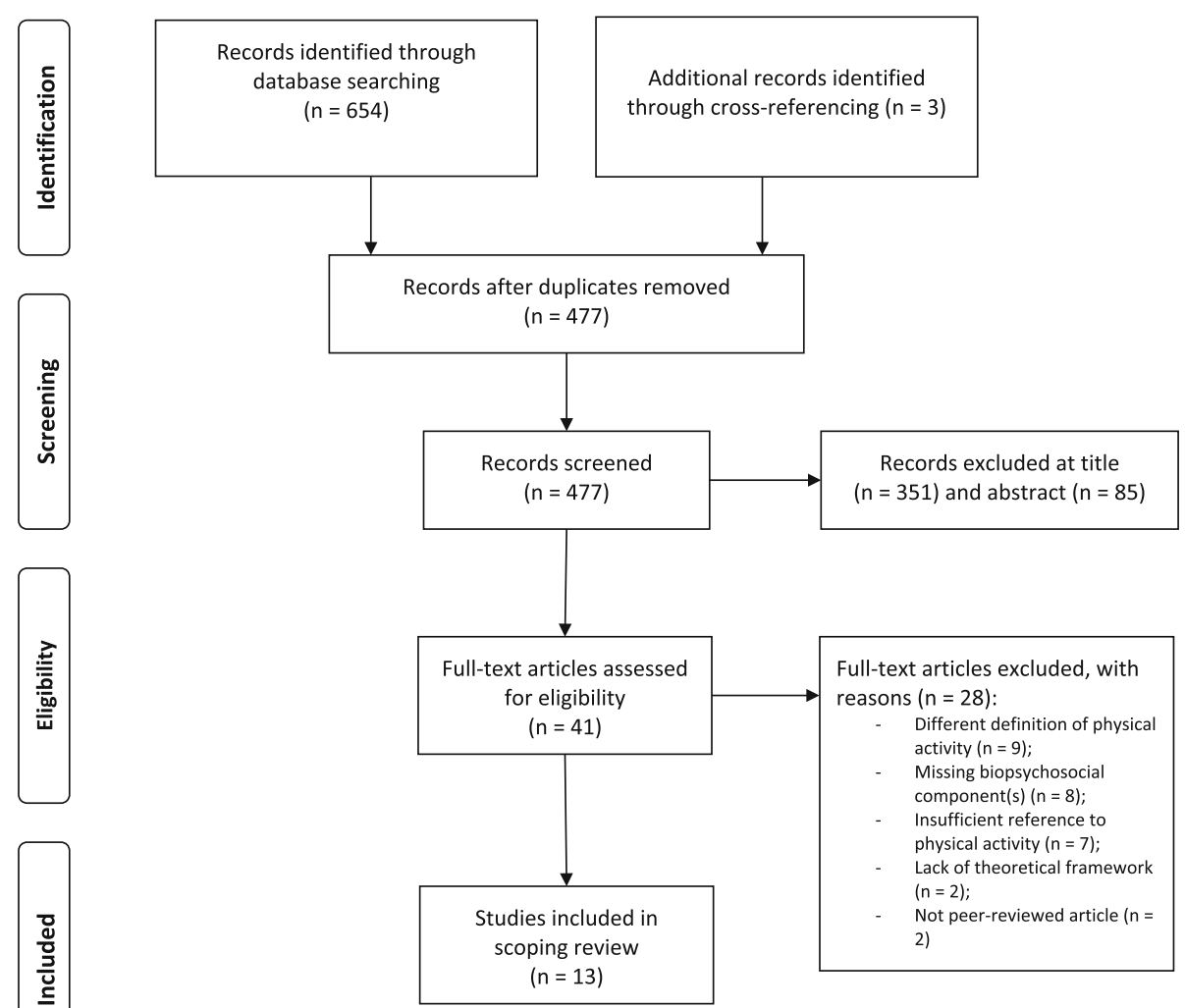

Fig. 1 PRISMA flow diagram

bio/physio/genetic, psycho/mental, and socio/cultural/ environmental); (ii) they solely focused on exercise and sports in organized and structured settings (i.e., papers examining determinants of sport participation or effects of exercise interventions).

Since we aimed to examine how the "biopsychosocial" is conceptualized in PA research, we did not use any restrictions related to the term "biopsychosocial." As long as papers referred to a model that integrated biological, psychological, and social aspects in the context of PA behavior, they were included in the present scoping review, even if the original authors did not explicitly use the term "biopsychosocial" in their work.

At each stage of the screening process, articles that did not meet the inclusion criteria were excluded. Reasons for exclusion of full-texts are depicted in Fig. 1. The first and second author screened all titles and abstracts independently. To assess inter-rater reliability during the screening process, we calculated the kappa statistic [24]. When there were disagreements about the eligibility of particular articles, agreement was reached through a process of constructive debate between all authors.

\section{Study Synthesis}

Extracted data included the article type, meaning whether they were empirical papers or non-empirical work (i.e., literature reviews, commentaries, theoretical work), the article's overarching objective, and the study's underlying theoretical model or approach. Thereby, we extracted the model's components and identified which specific variables the original study authors operationalized among the respective components, how PA was integrated into the model, and how the nature of the relationship between the model components was depicted (see Table 1). We narratively synthesized our findings.

\section{Results}

\section{Literature Identification}

The database search produced a total of 654 results. Three additional records were identified through screening reference sections of eligible articles. After removing duplicates, 477 articles remained. The title screening excluded 351 articles and the abstract screening excluded 85 articles that did not meet the inclusion criteria. Cohen's kappa was 0.82 for the title screening, and 0.81 
Table 1 Summary of included articles

\begin{tabular}{|c|c|c|}
\hline $\begin{array}{l}\text { Authors } \\
\text { (year) } \\
\text { [citation } \\
\text { no.] }\end{array}$ & Research objective & $\begin{array}{l}\text { Theoretical moc } \\
\text { or approach }\end{array}$ \\
\hline \multicolumn{3}{|c|}{ Empirical articles } \\
\hline $\begin{array}{l}\text { Flannery } \\
\text { et al. } \\
\text { (2019) } \\
{[25]}\end{array}$ & $\begin{array}{l}\text { Examining the link between social, } \\
\text { biological, behavioral, and psychological } \\
\text { factors and level of PA in healthy } \\
\text { pregnant women. }\end{array}$ & $\begin{array}{l}\text { Biopsychosocial } \\
\text { model }\end{array}$ \\
\hline
\end{tabular}

Hearst Examining factors that predict PA in et al. children and adolescents between 10 (2012) and 16 years

[26]

Lämmle Examining the association between et al. distal and proximal factors that

(2013) influence PA, sedentary behavior, and

[27] eating behavior and relationship to health in children and adolescents between 4 and 17 years

McNeil Examining the relationship between et al. individual factors and factors of the (2006) social and physical environment on PA [28] within a group of Afro Americans and Caucasian Americans

Socio-ecological model

Biopsychosocia model

Socio-ecological model

Biopsychosocial model

et al.

(2010)

[29]
Examining the relationship between PA and the three components of successful aging within a group of 60 years of age and above
Biological: Gravidity, BMI

Behavioral: Smoking, alcohol, folate

intake, fruit and vegetables, fish

Psychological: Anxiety, stress,

depression, response to pregnancy

Social: Age, ethnicity, marital status, employment status, accommodation, socioeconomic status, maternity service

Intrapersonal: Self-efficacy, PA enjoyment, barriers to PA

Behavioral: Screen time; sports team participation

Social: Parent and peer support

Physical environment: Home PA

environment, neighborhood safety,

walkability

Individual-level measure (covariates):

Pubertal status, age, sex, race, weight,

height, percent body fat, demographic and socioeconomic status

Distal (environmenta): Socio-economic status, rural-urban differences, immigration background

Proximal I (interpersonal): PA of

relatives and peers

Proximal II (intrapersonal): Motivation,

psychopathological problems, quality of life

Behavioral: PA, eating patterns,

sedentary behavior

Objective health and physical fitness:

BMl, body fat, blood pressure,

cholesterol

Health and health complaints: Pain,

psychosomatic and physical

complaints, subjective health

Individual: Self-efficacy, motivation

Social environmental: Social support

Physical environmental: Neighborhood quality, access to facilities

Sociodemographic: Age, race, ethnicity, sex, household income, education

Low probability of disease or diseaserelated disability: Presence of chronic conditions (respiratory diseases, inflammatory diseases, inflammatory diseases, cardiovascular diseases, metabolic and related diseases, cancers, incontinence, back problems) High cognitive and physical functional capacity: Assistance with instrumental and general activities of daily living Active social engagement with life: Time spent in sedentary activities, sense of belonging to the local community, involvement in voluntary social organizations

\section{Integration Relationships or interactions between components}

\author{
(Possible) Unidirectional \\ determinants influence of the \\ components on \\ PA levels \\ (Possible) Unidirectional \\ determinants influence of the \\ respective \\ components on \\ PA
}

(Possible) Interrelationships effects and between determinants components 
Table 1 Summary of included articles (Continued)

\begin{tabular}{|c|c|c|c|c|c|}
\hline $\begin{array}{l}\text { Authors } \\
\text { (year) } \\
\text { [citation } \\
\text { no.] }\end{array}$ & Research objective & $\begin{array}{l}\text { Theoretical model } \\
\text { or approach }\end{array}$ & Model's components & $\begin{array}{l}\text { Integration } \\
\text { of PA }\end{array}$ & $\begin{array}{l}\text { Relationships or } \\
\text { interactions } \\
\text { between } \\
\text { components }\end{array}$ \\
\hline
\end{tabular}

no.]

Covariates: Sex, age, total household income

Roekel low and moderate-to-vigorous PA and

et al. the health-relevant quality of life in

(2015) former colorectal cancer patients

[32] van Examining the relationship between

\section{Biopsychosocial \\ model \\ (based on \\ International \\ Classification of \\ Functioning, \\ Disability, and \\ Health)}

model of

participation in PA

et al.

(2011)

[33]

approach for lifelong sport participation and PA using a critical perspective on key theories
Biopsychosocia
Kanavaki Systematic review of barriers and et al. facilitators to participation in PA in

(2017) adults with gon- or coxarthrosis

[34]

Kanning Description of a biopsychosocial model and for successful aging and its effects on Schlicht subjective well-being

(2008)

[36]
Biopsychosocial model after Engel [35]
Biopsychosocial model of successful aging

\section{Cancer-specific quality of life: Global health; physical, role and social functioning; self-reported fatigue; anx- iety and depression; disability Other factors: Sociodemographic characteristics (sex, age, education level, smoking status), BMl, presence of comorbidities, clinical characteristics}

Biological: Biological maturation readiness, hormonal change

Psychological: Psychological

development, pressure

Social: Transitions, access, peer, social expectations

Physical health: Pain, physical capacity, age, physical fitness

Intrapersonal/psychological: Experience and beliefs about PA, behavioral regulation and attitude, emotions Social environment: Health professional, social support

Physical environment: Cost, accessibility, temperature, safety issues

Personal disposition: Physiological constitution/genotype, personality, socialization/sports-biography, socioeconomic status

Social-structural constraints:

Stereotypes, behavior setting, offers/ facilities

Psychological: Cognition, emotion, goals, need satisfaction, subjective well-being
King and Discussion of advantages of a healthy King lifestyle, and current problems and (2010) challenges and their significance for [37] science, politics, and practice

ts regarding open spaces, parks, et al. and PA in comparison to younger (2018) [38]
Socio-ecological model

Biopsychosocial model of health

Personal: Sex, age, genes, beliefs, enjoyment of PA, motivation, health status, function, well-being Individual behavior: Types of PA, sedentary behaviors

Social/cultural: Modeling/support for PA, social norms and cultural values, institutions, mass media

Environment/ Policy: Neighborhood, infrastructure, urban planning, health care, policies

Biological/physical needs: Self-reported physical health, stress, good accessibility, places to rest, ergonomic features Psychological needs: Choice, feelings of safety

Social needs: Foster engagement in social activities, social support, space for social interaction

Ecological model Intrapersonal: Demographics, biological, psychological, family situation
(Possible) Integration of PA

effects and into the model

determinants (with bidirectional relationships); Interrelationships between components

$\begin{array}{ll}\text { (Possible) } & \text { Unidirectional } \\ \text { determinants } & \text { influence of } \\ & \text { components on } \\ & \text { PA; } \\ & \text { Possible } \\ & \text { interactions } \\ & \text { between } \\ & \text { components over } \\ & \text { the life course } \\ \text { (Possible) } & \text { Unidirectional } \\ \text { determinants } & \text { influence of the } \\ & \text { respective } \\ & \text { components on } \\ & \text { PA; } \\ & \text { Reference to } \\ & \text { interrelationships } \\ & \text { between } \\ & \text { components } \\ & \text { Unidirectional } \\ \text { influence of PA } & \text { on subjective } \\ \text { (Possible) } & \text { well-being } \\ \text { effects } & \end{array}$

(Possible) Unidirectional determinants influence of the respective components on PA;

Change of components over the life course

(Possible) Reference to determinants interrelationships between components; Inclusion of the environment and the life course

(Possible) Unidirectional determinants influence of respective 
Table 1 Summary of included articles (Continued)

\begin{tabular}{|c|c|c|c|c|c|}
\hline $\begin{array}{l}\text { Authors } \\
\text { (year) } \\
\text { [citation } \\
\text { no.] }\end{array}$ & Research objective & $\begin{array}{l}\text { Theoretical model } \\
\text { or approach }\end{array}$ & Model's components & $\begin{array}{l}\text { Integration } \\
\text { of PA }\end{array}$ & $\begin{array}{l}\text { Relationships or } \\
\text { interactions } \\
\text { between } \\
\text { components }\end{array}$ \\
\hline [39] & behavior & & $\begin{array}{l}\text { Perceived environment: Safety, } \\
\text { attractiveness, comfort, crime, } \\
\text { convenience, accessibility } \\
\text { Behavior settings: Neighborhood, } \\
\text { recreation, home, transport, workplace, } \\
\text { school } \\
\text { Policy: Health care, transport policies, } \\
\text { school policies, traffic regulations, } \\
\text { neighborhood development policies, } \\
\text { media regulations }\end{array}$ & & $\begin{array}{l}\text { components on } \\
\text { PA }\end{array}$ \\
\hline $\begin{array}{l}\text { Stubbs } \\
\text { et al. } \\
(2015) \\
{[40]}\end{array}$ & $\begin{array}{l}\text { Systematic review on factors that } \\
\text { influence participation in PA in adult } \\
\text { patients with gon- or coxarthrosis }\end{array}$ & $\begin{array}{l}\text { Socio-ecological } \\
\text { model }\end{array}$ & $\begin{array}{l}\text { Demographic: Age, ethnicity, sex, BMl } \\
\text { Biological: Symptoms, pain, aerobic } \\
\text { capacity, strength, obesity, stiffness, } \\
\text { comorbidities, cardiovascular fitness } \\
\text { Behavioral and skill: Limb function/ } \\
\text { balance, gait speed, daily living } \\
\text { function } \\
\text { Psychological/cognitive/emotional: } \\
\text { Confidence, quality of life, depression, } \\
\text { intention to engage in PA } \\
\text { Social/cultural: Spouse, employment, } \\
\text { exercise in group, social and work } \\
\text { functioning } \\
\text { Physical environment: Outside } \\
\text { temperature, rain }\end{array}$ & $\begin{array}{l}\text { (Possible) } \\
\text { determinants }\end{array}$ & $\begin{array}{l}\text { Unidirectional } \\
\text { influence of } \\
\text { respective } \\
\text { components on } \\
\text { PA }\end{array}$ \\
\hline
\end{tabular}

for the abstract screening, suggesting a strong level of agreement [41].

For the remaining 41 articles, a full-text screening was conducted, excluding a total of 28 articles with justification (see Fig. 1). A total of 13 articles were included in the scoping review; with six being empirical papers and seven non-empirical papers (e.g., theoretical or conceptual articles) or systematic reviews (see Table 1). All of them were published in English.

\section{Theoretical Models or Approaches}

Concerning the underlying model, a total of eight articles pursued a purely biopsychosocial approach in the tradition of Engel's model, another five articles employed a socio-ecological approach (see Table 1). In line with our inclusion and exclusion criteria, we included articles based on a socio-ecological model if these models depicted at least a biological, psychological, and social component. The term "transdisciplinary" was used only in some articles that referred to the biopsychosocial model. In contrast, all articles that theoretically framed their work from a socio-ecological perspective included the term "transdisciplinary."

Most of the theoretical models refer to factors that influence behavior $(n=8)$, health $(n=3)$, or successful aging $(n=2)$. In empirical articles, four articles explicitly employed a biopsychosocial model $[25,27,29,32]$ and two a socio-ecological framework that comprised biological, psychological, and social factors [26, 28]. In non-empirical articles, the biopsychosocial model was referred to in four articles $[33,34,36,38]$, the socioecological model in three articles [37, 39, 40].

In empirical papers, a biopsychosocial or socioecological approach was employed to inform selection of correlates or assessed effects of PA behavior. Often, such a model also informed statistical modeling procedures, particularly with regard to contextual variables, moderator, and mediator effects. The original authors' justifications for using a biopsychosocial approach were quite similar to the justifications for using a socio-ecological model. In both cases, authors emphasized the comprehensive and interdisciplinary nature of such models, and their potential to simultaneously examine relationships between biological, psychological, and social factors [26$29,32]$. When using a socio-ecological approach, the original authors also highlighted the complex and dynamic nature of PA behavior [26, 28], a point that was not mentioned in articles based on a biopsychosocial model.

In non-empirical papers, particularly in (systematic) reviews, a biopsychosocial model or a socio-ecological model was used to synthesize and interpret the findings of original research [34, 38, 40]. Authors of review articles underlined that PA behavior is often influenced across multiple levels and that correlates at each level often overlap and interact with each other. Thus, for synthesizing original research findings on correlates of 
PA behavior, authors chose a biopsychosocial or socioecological framework to facilitate a more comprehensive and meaningful interpretation of the data of original studies. However, most original research was conducted from a unidimensional perspective. Thus, the reviews of Kanavaki et al. [34], Levy-Storms et al. [38], and Stubbs et al. [40] cannot answer questions about the interactions of factors at a biological, psychological, and social level. Collins et al. [33] described a multidimensional approach for lifelong sport participation and PA and used a biopsychosocial approach since it provides an effective basis for modeling and manipulating complex human behavior. The multidimensional nature of the biopsychosocial perspective was also emphasized by Kanning and Schlicht [36] in their description of a biopsychosocial model for successful aging. King and King [37] and Sallis et al. [39] employed a socio-ecological approach in their work to inform interventions, scientific research, and politics with regard to the promotion of a healthy lifestyle and active living.

\section{Integration of Physical Activity into the Model}

Concerning the integration of PA into the models, the majority of included papers $(n=9)$ focused on possible determinants or correlates of PA behavior, i.e., how the different components of a biopsychosocial or socioecological model affect PA. Two papers focused on how PA behavior affects the various components of a biopsychosocial model $[29,36]$; two articles analyzed both possible determinants of PA behavior and the effect of PA behavior on biopsychosocial indicators of health [27, 32]. Whereas the integration of PA into the biopsychosocial model was not uniform (i.e., PA was either included as the outcome variable, the independent variable, or both), all five articles grounded in a socio-ecological approach examined correlates of PA behavior.

\section{Variables Included in the Theoretical Models or Frameworks} The empirical and non-empirical articles did not differ with regard to the included variables in the theoretical models. Thus, in the following, we compare included variables in the models, which were explicitly termed "biopsychosocial," with those in the socio-ecological models.

The original biopsychosocial model in the tradition of Engel differentiates between biological, psychological, and social aspects. Some of the included articles (see also Table 1) directly used these terms to cluster their examined variables [25, 33, 34, 36, 38], whereas Lämmle et al. [27], and van Roekel et al. [32] group biological, psychological, and social variables into a category system that referred to distal, proximal, and behavioral factors and health indicators. Meisner et al. [29] employ the biopsychosocial model of successful aging by Rowe and
Kahn [31] and refer to the three components of successful aging rather than to biological, psychological, and social components.

When examining the variables that were subsumed under each category, the diversity of biopsychosocial approaches in the context of PA research became apparent. Depending on the article's objective, the original study author(s) grouped a great variety of variables under the respective category. Examined biological variables ranged from BMI to body fat, blood pressure, sex, presence of comorbidities, physical fitness to ergonomic features of outdoor park equipment. Examined psychological variables included perceived stress, motivation, psychopathological problems, cognitive capacity, psychological development, emotions, beliefs about PA, and feelings of safety. Social factors included marital status, employment status, socioeconomic status, PA of relatives and peers, social engagement, role and social functioning, life transitions, social support, stereotypes, behavior settings, and space for social interaction. Age was either assigned to the biological category or to the social category or was considered a covariate (as was also sometimes the case with sex).

Socio-ecological models assessed a similar variety of biological, psychological, and social variables; in addition, socio-ecological approaches placed a greater focus on behavioral (such as screen time, sports team participation, sedentary behaviors, or gait speed and limb function) and environmental aspects (such as neighborhood safety, walkability, outside temperature, and access to facilities). King and King [37] and Sallis et al. [39] included policy as a further component referring to urban planning, health care policies, traffic regulations, media regulations, transport policies, and school policies.

Three empirical articles referred to relationships or interactions between the individual components of the employed model. McNeill et al. [28] included unidirectional relationships between selected components of a socio-ecological model. Interactions between components were integrated into the biopsychosocial model in the articles of Lämmle et al. [27], and van Roekel et al. [32]. The systematic reviews of Kanavaki et al. [34], and Levy-Storms et al. [38] mentioned that interrelationships between various biopsychosocial correlates of engagement in PA behavior can be expected and should be considered in future research. The non-empirical papers of Collins et al. [33], and King and King [37] mentioned a possible change or adjustment of the components over the life course.

\section{Discussion}

The overall aim of the scoping review was to examine how the "biopsychosocial" has been conceptualized in the existing literature on PA behavior. Overall, we only 
found a limited number of studies that analyzed PA behavior from a biopsychosocial perspective. Notably, only six of the included 13 articles were empirical studies concerned with PA behavior.

\section{Underlying Theoretical Models or Frameworks}

Broadly speaking, the models in the original articles either depicted correlates of PA behavior, or the influence of PA on various biopsychosocial outcomes such as health, quality of life, or successful aging. Several justifications for using a biopsychosocial model or a similar theoretical approach (i.e., transdisciplinary approaches or social-ecological models), which also focuses on biological, psychological, and social aspects, were found in the original articles. Nearly all articles pointed out that a biopsychosocial perspective is fitting to simultaneously examine relationships between biological, psychological, and social dimensions with regard to correlates and effects of PA behavior. Thereby, authors of original articles often referred to the biopsychosocial model's potential to describe a phenomenon from a multidimensional perspective that takes interactions of various factors into account.

A total of five included articles employed the socioecological model in the tradition of Bronfenbrenner [42]. Even though socio-ecological models are models in their own right, we included these articles in the present review as long as it was apparent that biological, psychological, and social factors were part of such a framework; thereby, this work implicitly followed a biopsychosocial perspective. Socio-ecological models in the included articles were concerned with explaining PA behavior or describing a wide range of factors that potentially influence PA behavior in specific populations [43]. Thus, socio-ecological frameworks are used to model not only behavioral influences within and between individuals but also environmental and political influences. Withinperson influences often include the biological and psychological components whereas the social and cultural components are summarized under influences between persons or as environmental influences [43].

In contrast to socio-ecological approaches, articles that referred to the biopsychosocial model in the tradition of Engel were not only concerned with influences on PA behavior but also focused on possible biopsychosocial effects of PA behavior; thus extending the scope of the socio-ecological model through considering PA behavior either as the outcome variable or the independent variable.

Taken together, even though both models are theoretical frameworks in their own right, they share a transdisciplinary perspective on PA behavior. When looking at the broader field of health and illness research, there have even been attempts to combine Engel's biopsychosocial model with Bronfenbrenner's ecological model in order to better explain health- and illnessrelated changes in a person [44]. The present scoping review demonstrates the various ways that PA behavior can be included either in a biopsychosocial model or a socio-ecological framework, with neither one offering a concrete basis for the inclusion of PA.

\section{Variables Included in the Biopsychosocial and Socio- ecological Models}

The models that were used in the reviewed articles differed to a large extent with regard to the integrated components and the assessed variables. While some articles followed the original classification into biological, psychological, and social aspects, other articles used different categories such as proximal, distal, interpersonal, intrapersonal, behavioral, environmental, and cultural aspects. These different overarching categories directly go back to the nature of the included models. Whereas most articles that were based on the biopsychosocial model in the tradition of Engel employed the traditional categorization into biological, psychological, and social aspects, socio-ecological models directed attention also to environmental and policy features. Since socioecological models in included articles were mainly adopted for studying PA behavior in specific places and populations, a greater focus on the characteristics of places that hinder or facilitate PA behavior can be observed.

Overall, a broad variety of variables was included in the theoretical frameworks. The reasons for such a variety might be traced back to the objectives of the included articles and to the study samples. For example, different aspects may be of significance or of greater significance for the prediction of PA in children and adolescents [26] than for the effects of PA on the quality of life of former colorectal cancer patients [32]. Even though this observed variety of variables makes a clear comparison of approaches nearly impossible, it also demonstrates the potential of a biopsychosocial perspective to be used in a variety of research contexts and to inform transdisciplinary PA research.

The systematic integration of relationships between the biological, psychological, and social components is emphasized in the original work of Engel [7, 35]. However, only few of the included articles empirically analyzed interactions between the individual components $[27,28,32]$. Complex statistical analyses such as path analyses and bivariate correlations [27], moderation and mediation analyses [27, 28], structural equation modeling with a focus on testing theoretical relationships between latent constructs [28], and multivariable linear regression models with subgroup analyses [32] were 
performed to analyze such complex interactions of model components.

All in all, the aforementioned points illustrate the challenges that arise when applying a biopsychosocial perspective on complex phenomena such as health and/or PA. These challenges become even more complex when differences between individuals and within individuals over time are taken into account.

\section{Implications for Future Research}

The present scoping review shows the benefits of a biopsychosocial perspective on PA behavior. Both the empirical and non-empirical articles in this scoping review advocate for a multidimensional and complex perspective in research on the biopsychosocial correlates and effects of PA behavior. Due to the complex nature of PA behavior, research on correlates and effects of PA should be informed by theoretical approaches that aim to capture this complexity, either with regard to the interactions of multiple correlates of PA behavior or with regard to the complex and interrelated effects of PA.

Even though it seems to be common sense that PA behavior is complex and influenced by a myriad of factors, most empirical evidence is still not based on comprehensive approaches. This point is also demonstrated by the relatively small number of empirical studies identified in this review that explicitly follow a transdisciplinary perspective when examining the correlates of PA behavior.

The included empirical research based on a biopsychosocial perspective convincingly demonstrates that no one factor explains PA behavior; rather it is an interaction of factors at different levels. Grounding empirical research on sound theoretical frameworks, such as the biopsychosocial model or the socio-ecological model, facilitates the identification of important contextual factors and potential confounding and moderating effects when examining influences on PA behavior. However, one major drawback of the models that we analyzed in our scoping review was their missing focus on the complex interactions between the various factors. It is precisely these interactions that add great value compared to a unidimensional view when examining such a complex, multidimensional, and dynamic phenomenon as PA behavior. In future research, approaches are needed that aim to capture these interaction effects.

Thus, for future transdisciplinary PA research, it is a reasonable approach to examine multilevel influences on PA behavior. Such an approach to PA behavior necessitates application of complex statistical procedures (such as growth curve modeling, structural equation modeling, latent class analysis, etc.) that allow identification of intraand inter-individual and contextual differences as well as dynamic interactions between different factors. Additionally, a multilevel perspective also requires long-term transdisciplinary work from different scientific disciplines such as sports medicine, epigenetics, health psychology, sport sociology, and public health, employing different methodological approaches to capture the full complexity of the underlying phenomenon (i.e., PA behavior). Through considering factors at different levels and particularly their interactions, which necessarily makes such research more complex, it becomes possible to better understand influences on PA behavior. Knowledge gained through such a transdisciplinary perspective will help to develop and implement PA promotion programs, public health strategies, interventions, and policies that more effectively target specific contributing factors for PA behavior in at-risk groups for low PA levels.

Transdisciplinary approaches are also required for recognizing and understanding the effects of PA behavior on an individual and societal level. Asking solely for effects on one level (such as the physiological level) might overlook or even disregard important benefits of PA on other levels (such as the psychological or social) that might also affect health and quality of life, or the outcomes of rehabilitation programs or treatment strategies. Research on the effectiveness of health-related behavioral interventions might also be improved if it considers the biological, psychological, and social benefits of PA.

While transdisciplinary approaches in PA research are more common in some disciplines (e.g., sports psychology and sports medicine or social-psychology), the collaboration between others is still missing. One such transdisciplinary approach might be between the evolving field of epigenetics and sociology and psychology. Outside the field of sport science, researchers have already begun to argue that epigenetics should expand its scope beyond molecular biology research only [45], and rather complement its research agenda with sociological and psychological models, which might help capture environmental influences on gene expression [2]. By including epigenetics as a sub-aspect of the biological component, future transdisciplinary PA research could generate new insights into the genesis of many healthrelated phenomena through a focus on interactions between genetics and PA [46], or the influence of the environment on gene expression in the context of adaptations to training, exercise, and PA [47].

\section{Limitations of the Scoping Review}

Some important limitations of our review need to be considered. The first limitation lies in the small number of included studies. The relatively strict inclusion and exclusion criteria could be a reason for this. However, they were necessary to limit the scope of the review. We acknowledge that further insights could be gained by broadening the search strategy, i.e., also including the areas of exercise and sports. 
Additionally, data may be incomplete because some studies might have been published in another language or indexed in other databases. However, through screening of reference sections of eligible studies, we aimed to lower the risk of bias across studies.

Since we solely included the terms biopsychosocial and transdisciplinary in our search, articles that only implicitly employ such a perspective and do not use either of the terms were not included in this review. As a consequence, often cited papers such as the articles from Bauman et al. [48], or Bryan et al. [46] have not been identified in our search. Bauman et al. [48], for example, examined correlates and determinants of PA with the goal to develop a multi-level ecological model for understanding the causes of PA behavior. The authors aimed to develop a model that also takes into account how etiological factors differ between PA domains, areas of life in which activity is observable, and country, age, sex, ethnic origin, and socioeconomic status. Bauman et al. [48] concluded that individual-level factors such as age, sex, health status, self-efficacy, and previous PA are consistent correlates of PA, but the physical and social environments, such as policy, economic conditions, societal norms, urbanization, industrialization, or interpersonal relations are also important determinants of PA behavior. Not least, they also argued that a genetic and evolutionary physiological component has to be considered when analyzing the correlates of PA behavior. Against this background, the model of Bauman et al. [48] can clearly be considered a biopsychosocial model despite the fact that they did not mention this term in their paper.

Similarly, the transdisciplinary model of PA behavior by Bryan et al. [46] also offers an exemplary approach for a multi-perspective analysis of PA. Bryan et al. [46] modeled the complex interactions of different components for behavioral change using the example of an intervention that promotes engagement in PA. In this regard, they explicitly considered the individuality of people and thereby individual differences as a reason to employ a transdisciplinary approach. They not only included a physiological, a genetic, a psychological, and a behavioral component into their theoretical model but also considered bidirectional relationships between components in order to explain (possible) effects and determinants of PA. However, this is a fundamental difference to the model of Bauman et al. [48], they completely abandoned the social component in their transdisciplinary approach. Although the article is generally very informative and helpful for designing intervention programs, the lack of a social component is a relevant shortcoming, as PA behavior is highly influenced by social and environmental factors.

\section{Conclusion}

This scoping review provides a first overview of biopsychosocial models in the context of transdisciplinary PA research. In principle, biopsychosocial models refer to PA behavior from a holistic perspective including biological, psychological, and social aspects and beyond such as the wider environment or politics. Therewith, in principle, a biopsychosocial approach yields great potential for an exhaustive, transdisciplinary perspective on PA behavior. The findings of the present scoping review illustrate that socio-ecological models mainly focus on the determinants or correlates of PA behavior, whereas biopsychosocial models in the tradition of Engel adopt a broader perspective referring both to the determinants and to the effects of PA behavior. Additionally, biopsychosocial models mostly focus on promoting health through PA.

The included articles illustrate that the adoption of a biopsychosocial perspective may assist to capture and understand the complex phenomenon of PA behavior. One of the main advantages of a biopsychosocial perspective in health research is that it allows consideration of individuality and individual differences on different levels. Thus, the observed heterogeneity with regard to the employed models and with regard to the assessed variables at the biological, psychological, and social levels can be considered a strength of the biopsychosocial perspective. Individuals of different ages with different health status and different performance capabilities are likely to display inter-individual variation with regard to the determinants and effects of PA. It is also likely that the determinants and effects of PA behavior change over the life course of an individual, thus displaying intraindividual variation. Consequently, inter- and intraindividual differences at a biological, psychological, and social level are likely to play an important role in maintaining an active lifestyle as well as in individual training responses, or in predicting improvements in athletic performance [2, 33].

Taken together, the included articles may give a first idea on how to holistically conceptualize PA, which might be of help when designing programs for the promotion of PA. In this sense, the present scoping review not only shows the potential of looking at PA behavior from a biopsychosocial perspective but also highlights the need for further transdisciplinary research in this area.

\footnotetext{
Acknowledgements

In case of publication, we acknowledge support by Open Access Publishing Fund of the University of Tübingen.

Authors' Contributions

$\mathrm{J}, \mathrm{VH}$, and AT conceptualized and designed the scoping review. VH conducted the search and the screening of the articles as part of her undergraduate thesis supervised by AT. JJ and AT assisted in the decisionmaking process regarding inclusion and exclusion of studies. $\mathrm{VH}$ extracted all
} 
data and proposed the initial data synthesis under close supervision of J J and AT. JJ and AT wrote the first English draft of the manuscript. JJ, VH, and AT revised the manuscript. JJ, VH, and AT approved the submitted version.

\section{Authors' Information}

$\mathrm{JJ}$ is a research assistant and PhD student at the Institute of Sport Science at the University of Tübingen, a member of the LEAD Graduate School and Research Network, and of the Interfaculty Research Institute for Sport and Physical Activity at the University of Tübingen. She holds a Master of Science degree in Kinesiology and a Master of Science degree in Family and Consumer Sciences with an emphasis on nutrition from Lamar University, Texas.

$\mathrm{VH}$ is a graduate student and student assistant at the Institute of Sport Science at the University of Tübingen. The submitted work is part of her undergraduate thesis, supervised by AT.

AT is professor and director of the Institute of Sport Science at the University of Tübingen. He leads the work group social and health sciences at the Institute and is a speaker of the Interfaculty Research Institute for Sport and Physical Activity at the University of Tübingen. He is PI of the interdisciplinary PhD network "Individual response to physical activity - a transdisciplinary approach (iReAct)," which comprises researchers from the Department of Sports Medicine, the Institute of Sports Science, and the Department of Psychosomatic Medicine and Psychotherapy at the University of Tübingen.

\section{Funding}

The authors did not receive any funding for the conduct of this study and the preparation of this manuscript. Open Access funding enabled and organized by Projekt DEAL.

\section{Availability of Data and Materials}

Data analyzed during this scoping review are included in this published article (in the tables summarizing the included studies). Reasons for the exclusion of studies can be requested from the corresponding author.

\section{Ethics Approval and Consent to Participate}

Not applicable

\section{Consent for Publication}

Not applicable

\section{Competing Interests}

The authors, Jannika John, Vanessa Haug, and Ansgar Thiel, declare that they have no competing interests relevant to the content of this review.

Received: 19 February 2020 Accepted: 1 October 2020

Published online: 17 October 2020

\section{References}

1. Hummel A, Krug J, Rohrberg K, Rausch L. Impulse und Perspektiven für die Entwicklung der Sportwissenschaft [Inputs and perspectives for the development of sport science]. In: Diesner T, Ketting M, Scupin O, Wessel KF, editors. Humanontogenetik - Interdisziplinäre Theorie und Brücke in die Praxis [Humantogenetics - Interdisciplinary theory and a bridge to praxis]. Berlin: Lagos Verlag; 2016. p. 171-85.

2. Munz B, Thiel A. Individualisiertes Training-ein biopsychosozialer Ansatz [Individualized training - a biopsychosocial approach]. Deutsche Zeitschrift für Sportmedizin. 2018;69.

3. Frances A. Resuscitating the biopsychosocial model. The Lancet Psychiatry 2014;1(7):496-7.

4. World Health Organization. International classification of functioning, disability and health. Genf: WHO Library Cataloguing-in-Publication Data; 2001.

5. Wade DT, Halligan PW. The biopsychosocial model of illness: a model whose time has come. Clinical Rehabilitation. 2017:31(8):995-1004.

6. Degenhardt A, Thiele A. Biomedizinische und biopsychosoziale Modelle [Biomedical and biopsychosocial models]. In: Hurrelmann K, Kolip P, editors. Geschlecht, Gesundheit und Krankheit: Männer und Frauen im Vergleich [Sex, health and illness: a comparison between men and women]. Bern: Huber; 2002. p. 87-103.

7. Engel GL. The need for a new medical model: a challenge for biomedicine. Science. 1977;196(4286):129-36.
8. Egger JW. Grundlagen der "Psychosomatik". Zur Anwendung des biopsyhcosozialen Krankheitsmodells in der Praxis [The basics of "psychosomatics": on the application of a biopsyhcosocial model of illness in clinical settings]. Psychologische Medizin. 2008;19(2):12-22

9. Gropper H, John JM, Sudeck G, Thiel A. The impact of life events and transitions on physical activity: a scoping review. PLoS One. 2020;15(6): e0234794.

10. Gabriel KKP, Morrow JR, Woolsey A-LT. Framework for physical activity as a complex and multidimensional behavior. Journal of Physical Activity and Health. 2012;9(s1):S11-S8.

11. Bergman S. Public health perspective-how to improve the musculoskeletal health of the population. Best Practice \& Research Clinical Rheumatology. 2007:21(1):191-204.

12. Cavill N, Kahlmeier S, Racioppi F. Bewegung und Gesundheit in Europa: Erkenntnisse für das Handeln. Published in English by the World Health Organization Regional Office for Europe in 2006 under the title Physical activity and health in Europe: evidence for action. Vienna, Austria. 2010.

13. Thiel A, Seiberth K, Mayer J. Sportsoziologie. Ein Lehrbuch in 13 Lektionen [Sport sociology]. Meyer \& Meyer Verlag: Aachen; 2013.

14. Widmann M, Nieß AM, Munz B. Physical exercise and epigenetic modifications in skeletal muscle. Sports Medicine. 2019;49(4):509-23.

15. Brochado A, Oliveira-Brochado F, Brito PQ. Effects of personal, social and environmental factors on physical activity behavior among adults. Revista Portuguesa de Saúde Pública. 2010;1:7-17.

16. Epstein LH. Integrating theoretical approaches to promote physical activity. American Journal of Preventive Medicine. 1998;15(4):257-65.

17. King AC, Stokols D, Talen E, Brassington GS, Killingsworth R. Theoretical approaches to the promotion of physical activity: forging a transdisciplinary paradigm. American Journal of Preventive Medicine. 2002;23(2):15-25.

18. Tricco AC, Lillie E, Zarin W, O'Brien KK, Colquhoun H, Levac D, et al. PRISMA extension for scoping reviews (PRISMA-SCR): checklist and explanation. Annals of Internal Medicine. 2018;169(7):467-73.

19. Munn Z, Peters MDJ, Stern C, Tufanaru C, MCArthur A, Aromataris E. Systematic review or scoping review? Guidance for authors when choosing between a systematic or scoping review approach. BMC Med Res Methodol. 2018:18(1):143.

20. Levac D, Colquhoun $H, O^{\prime} B r i e n ~ K K$. Scoping studies: advancing the methodology. Implementation Science. 2010;5(69).

21. Biddle SJH, Mutrie N. Psychology of physical activity: determinants, wellbeing and interventions. Oxon: Routledge; 2001.

22. Caspersen CJ, Powell KE, Christenson GM. Physical activity, exercise, and physical fitness: definitions and distinctions for health-related research. Public Health Rep. 1985;100(2):126-31.

23. Katzmarzyk PT. Physical activity, sedentary behavior, and health: paradigm paralysis or paradigm shift? Diabetes. 2010;59(11):2717-25.

24. Belur J, Tompson L, Thornton A, Simon M. Interrater reliability in systematic review methodology: exploring variation in coder decision-making. Sociological methods \& research. 2018;0049124118799372.

25. Flannery C, Dahly D, Byrne M, Khashan A, McHugh S, Kenny LC, et al. Social, biological, behavioural and psychological factors related to physical activity during early pregnancy in the Screening for Pregnancy Endpoints (Cork, Ireland) cohort study. BMJ open. 2019;9(6):e025003.

26. Hearst MO, Patnode CD, Sirard JR, Farbakhsh K, Lytle LA. Multilevel predictors of adolescent physical activity: a longitudinal analysis. International Journal of Behavioral Nutrition and Physical Activity. 2012;9(1):1-10.

27. Lämmle L, Woll A, Mensink G, Bös K. Distal and proximal factors of health behaviors and their associations with health in children and adolescents. International Journal of Environmental Research and Public Health. 2013; 10(7):2944-78.

28. McNeill LH, Wyrwich KW, Brownson RC, Clark EM, Kreuter MW. Individual, social environmental, and physical environmental influences on physical activity among black and white adults: a structural equation analysis. Annals of Behavioral Medicine. 2006;31(1):36-44.

29. Meisner BA, Dogra S, Logan AJ, Baker J, Weir PL. Do or decline? Comparing the effects of physical inactivity on biopsychosocial components of successful aging. Journal of Health Psychology. 2010;15(5):688-96.

30. Rowe JW, Kahn RL. Human aging: usual and successful. Science. 1987;237:143-9.

31. Rowe JW, Kahn RL. Successful aging. New York: Pantheon Books; 1998.

32. van Roekel EH, Bours MJ, Breedveld-Peters JJ, Meijer K, Kant I, Van PADB, et al. Light physical activity is associated with quality of life after colorectal cancer. Medicine and Science in Sports and Exercise. 2015;47(12):2493-503. 
33. Collins D, Bailey R, Ford PA, MacNamara Á, Toms M, Pearce G. Three Worlds: new directions in participant development in sport and physical activity. Sport, Education and Society. 2012;17(2):225-43.

34. Kanavaki AM, Rushton A, Efstathiou N, Alrushud A, Klocke R, Abhishek A, et al. Barriers and facilitators of physical activity in knee and hip osteoarthritis: a systematic review of qualitative evidence. BMJ open. 2017; 7(12):e017042.

35. Engel GL. The clinical application of the biopsychosocial model. American Journal of Psychiatry. 1980;137(5):535-44.

36. Kanning M, Schlicht W. A bio-psycho-social model of successful aging as shown through the variable "physical activity". European Review of Aging and Physical Activity. 2008;5(2):79-87.

37. King AC, King DK. Physical activity for an aging population. Public Health Reviews. 2010;32(2):401-26.

38. Levy-Storms L, Chen L, Loukaitou-Sideris A. Older adults' needs and preferences for open space and physical activity in and near parks: a systematic review. Journal of Aging and Physical Activity. 2018;26(4):682-96.

39. Sallis JF, Cervero RB, Ascher W, Henderson KA, Kraft MK, Kerr J. An ecological approach to creating active living communities. Annual Review of Public Health. 2006;27:297-322.

40. Stubbs B, Hurley M, Smith T. What are the factors that influence physical activity participation in adults with knee and hip osteoarthritis? A systematic review of physical activity correlates. Clinical Rehabilitation. 2015;29(1):80-94.

41. McHugh ML. Interrater reliability: the kappa statistic. Biochemia medica: Biochemia medica. 2012;22(3):276-82.

42. Bronfenbrenner $U$. The ecology of human development. Experiments by nature and design. Cambridge: Harvard University Press; 1979.

43. Sallis JF, Owen N, Fisher EB. Ecological models of health behavior. In: Glanz K, Rimer BK, Viswanath K, editors. Health behavior and health education Theory, Research, and Practice. 4th ed. San Francisco: Wiley; 2008. p. 456-85.

44. Lehman BJ, David DM, Gruber JA. Rethinking the biopsychosocial model of health: understanding health as a dynamic system. Social and Personality Psychology Compass. 2017;11(8):e12328.

45. Loi M, Del Savio L, Stupka E. Social epigenetics and equality of opportunity. Public Health Ethics. 2013;6:142-53.

46. Bryan AD, Magnan RE, Nilsson R, Marcus BH, Tompkins SA, Hutchison KE. The big picture of individual differences in physical activity behavior change: a transdisciplinary approach. Psychology of Sport and Exercise. 2011:12(1):20-6.

47. Landecker H, Panofsky A. From social structure to gene regulation, and back: a critical introduction to environmental epigenetics for sociology. Annual Review of Sociology. 2013;39(1):333-57.

48. Bauman AE, Reis RS, Sallis JF, Wells JC, Loos RJF, Martin BW, et al. Correlates of physical activity: why are some people physically active and others not? The Lancet. 2012;380(9838):258-71.

\section{Publisher's Note}

Springer Nature remains neutral with regard to jurisdictional claims in published maps and institutional affiliations.

\section{Submit your manuscript to a SpringerOpen ${ }^{\circ}$ journal and benefit from:}

- Convenient online submission

- Rigorous peer review

- Open access: articles freely available online

- High visibility within the field

- Retaining the copyright to your article

Submit your next manuscript at $\boldsymbol{\nabla}$ springeropen.com 